\title{
Un poema hebreo de Alfonso de Zamora en alabanza de la versión latina bíblica de Pedro Ciruelo
}

\author{
Carlos del VALLE \\ Instituto de Filología, CSIC, Madrid
}

En la polifacética personalidad del converso zamorano Alfonso de Zamora ${ }^{1}$ hay un aspecto que ha quedado oculto hasta el presente. Me refiero a sus escarceos poéticos en lengua hebrea ${ }^{2}$. En realidad sólo se nos ha transmitido un poema, literariamente de poca calidad, pero interesante para conocer la formación humanística del converso zamorano y para ilustrar las ideas e inquietudes de los teólogos y exegetas contemporáneos sobre la Vulgata y el texto hebreo bíblico, pocos años antes de que el Concilio tridentino se pronunciara sobre el tema.

\footnotetext{
1 Véase mi artículo «Notas sobre Alfonso de Zamora», Sefarad 47 (1987) págs. 173-180 y la bibliografía allí indicada.

2 Alfonso de Zamora es también autor de un opúsculo en verso castellano: «Loor de virtudes nuevamente impresso, añadido y emendado, Compuesto por el maestro Alonso de Çamora regente en la Universidad de Alcalá. Alcalá de Henares, Miguel de Eguía, 1525» (Biblioteca Nacional, Madrid [= BNM], R-13616; $1^{a}$ ed. 1524). Así describe el autor el contenido de las tres partes de la obra: «La primera es hablar del tiempo breve desta vida y de su mucho trabajo, en remedio del qual es la sciencia por los provechos que della se siguen. $Y$ en la segunda parte trata contra los siete pecados mortales por su orden. Y en la tercera parte trata de algunas doctrinas generales». Las sentencias, de carácter moral, están sacadas de la Escritura o de los filósofos: «Como águila caudalosa / buela el tiempo de corrida / y con él va nuestra vida / sobre ser muy trabajosa». En muchas ocasiones hace referencia a episodios del Antiguo Testamento: «El tribu de Benjamín / por su maldad imprudente / pereció muy crudamente / en gran batalla a la fin». En los márgenes suele indicar las fuentes o la misma sentencia en latín.
} 
El poema referido se halla en el manuscrito hebreo núm. 589 de la Biblioteca Universitaria de Salamanca [= BUS], prácticamente ya al final del códice (fol. 274). El manuscrito contiene el Pentateuco hebreo de mano de Alfonso de Zamora ${ }^{3}$; pero lo novedoso es que el texto hebreo va acompañado por una traducción latina interlineal ad verbum atribuida al Dr. Ciruelo, que es el autor del prefacio latino (fols. $1 \mathrm{v}-3 \mathrm{v})^{4}$.

En el colofón se dice que el códice fue escrito para el sabio Pedro Ciruelo, del que se afirma que «no hay otro como él en España, en Francia y en el mundo entero» y que fue copiado y puntuado por Alfonso de Zamora en Alcalá de Henares, terminada la copia el 24 de julio de $1536^{5}$.

${ }^{3}$ Génesis, fols. 4r-72v; Exodo, fols. 72v-131r; Levítico, fols. 131v-171v; Números, fols. 171v-227v; y Deuteronomio, fols. 227v-273v.

${ }^{4}$ Pedro Ciruelo, de Daroca, se formó en Salamanca. A pesar de su escasez de medios, se trasladó a París para instruirse en teología y allí residió diez años, ganándose el sustento como profesor de matemáticas ( «Cum in adolescentia mea Parisiensium theologorum scholas perlustrarem atque ex professione matheseos mihi necessaria ad victum et indumenta compararem»). Fue catedrático de prima de Sto. Tomás en Alcalá y formó parte de la terna (con Silíceo y Miguel Carrascal) de preceptores del príncipe Felipe; él fue quien pronunció la oración fúnebre a la muerte de Antonio de Nebrija. Su amor por el estudio queda reflejado en testimonios como los siguientes: «librisque perpetue adherentem», «quidquid temporis studiis non impertiebatur, perire existimabat» (BNM, Ms. 8460, fol. 82a). Entre sus obras publicadas se cuentan: Prima pars logices ad veriores sensus textus Aristotelis (Compluti, Arnaldus Guillelmus de Brocario, 1519); Hexameron theologal sobre el regimiento medicinal contra la pestilencia (Alcalá de Henares, Arnao Guillén de Brocar, 1519); Apotelesmata Astrologiae Christianae (Compluti, Arnau Guillén de Brocar, 1521); Opusculum de Sphaera mundi (Compluti, Michael de Egía, 1526); Cursus quattuor mathematicarum artium liberalium (Compluti, Arnaldus Guillelmus de Brocario, 1526); Expositio libri missalis peregregia (Compluti, Michael de Eguía, 1528); Novus sed preclarissimus in posteriora analytica Aristotelis (Compluti, Michael de Eguía, 1529); Reprovación de las supersticiones y hechizerías (Salamanca, Pedro de Castro, 1538); Paradoxae quaestiones numero decem ... De cabala et magia Iudeorum in enarranda divina biblia (Salamanca 1538); Contemplaciones muy devotas sobre los misterios de la Pasión de nuestro Redentor (Alcalá de Henares, Juan de Brocar, 1547); Confessionario ... (Medina del Campo, Pedro de Castro, 1544); Arte de bien confessar para el confessor como para el penitente (Sevilla, Dominico de Robertis, 1548). Sobre Pedro Ciruelo véase M. BAtaillon, Erasme et Espagne, vol. I pág. 283 (trd. española, México 1966); François SECRET, «Pedro Ciruelo», Sefarad 19 (1959) págs. 48-77; y VALle "Alfonso de Zamora».

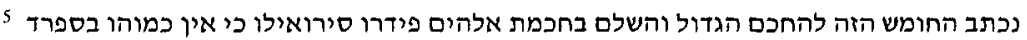

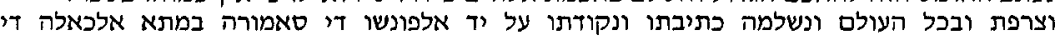
אינאריש בשנת אלף ותיקול ול"ו למנין ישועתינו שבח לאל היום כ"ד יום לחדש ג'וליו ביום שני באלחי... (fol. 273). 
En realidad la empresa de Ciruelo de hacer una versión latina literal interlineal de la Biblia hebrea había comenzado en el año 1526 con la traducción de Génesis (Ms. 118-Z-29 de la Biblioteca Universitaria de Madrid [= BUM]) y se había continuado con la versión de Lamentaciones, Daniel e Isaías en 1530 (Ms. 118-Z-28 de la misma BUM), con la versión completa del Pentateuco en 1536 (el referido manuscrito 589 de la BUS) y de nuevo del Éxodo en 1538 (Ms. 118-Z-30 de la BUM) ${ }^{6}$.

Pues bien, para honrar esta versión latina literal, «de verbo ad verbum», el copista del texto hebreo, esto es Alfonso de Zamora, compuso un poema hebreo y así lo declara él mismo en el encabezamiento hebreo del poema: 'Poema del amanuense de este códice ...'?

El amanuense del códice relaciona su composición poética con la obra de Ciruelo. De ahí que sea conveniente examinar primero el significado de la obra del famoso teólogo daroquense.

\section{LA TRADUCCIÓN LATINA LITERAL DE CIRUELO}

Pedro Ciruelo es el autor del prefacio latino que precede al texto hebreo del Pentateuco y a la traducción latina interlineal (Ms. 589 de la BUS). Así se abre el prefacio: «Admodum Reverendis ac multiformis sapientie cultoribus Rectori, Scholastico, Magistris ... Petrus Ciruelus Darocensis theologorum minimus salutem, et Pentateuchi Mosayci veridicam interpretationem ad verbum: hoc est, hebraicam simul et latinam».

En este prefacio, que es importante para conocer el alcance de la obra, Ciruelo dice que la revelación fue dirigida en primer lugar a los israelitas y en hebreo. Pero, debido a que todos los hombres han sido llamados a la salvación, fue nece-

6 Véanse los artículos de José Llamas, «Los manuscritos hebreos de la Universidad de Madrid», Sefarad 5 (1945) págs. 261-284; «Los manuscritos hebreos de la Universidad de Salamanca», Sefarad 10 (1950) págs. 263-279; y «Los manuscritos hebreos de la Real Biblioteca de San Lorenzo de El Escorial», Sefarad 1 (1941) págs. 12-14; asi como N. Allony - E. (F.) Kupfer, List of Photocopies in the Institute: Part II, Hebrew Manuscripts in the Libraries of Belgium, Denmark, the Netherlands, Spain and Switzerland (Jerusalem 1964) págs. 86-106.

7 Vid. infra la traducción del texto completo. 
sario traducir las Escrituras a las otras lenguas; se tradujeron así primero al griego, luego al arameo y por último al latín. Las traducciones al latín, sin embargo, no se hicieron desde el original hebreo, sino desde las versiones griega y caldea. De ahí que surgieran a veces variantes, disonancias, incluso errores, dificultando a veces el poder aducir correctamente un texto para fundamentar un dogma o una verdad de fe ${ }^{8}$.

Por esta razón San Jerónimo, conocedor del griego, del hebreo y del latín, se esforzó en hacer una traducción latina fidelísima del texto hebreo original, partiendo de ejemplares bíblicos correctos ${ }^{9}$. Pero la traducción de San Jerónimo, siendo literal y fiel, no fue, sin embargo, una traducción ad verbum ('palabra por palabra'), sino que procuró que el sentido de la traducción se correspondiera fielmente con el del original, aunque en esa traducción fuera a veces necesario cambiar el orden del original o quitar o añadir palabras, de manera que «in exemplari et exemplato idem penitus appareat sensus, quamvis sub diversis verbis» ${ }^{10}$.

San Jerónimo pensaba, tal como lo manifiesta en su prólogo al libro de Josué, que con su traducción se quitaba a los judíos la ocasión de calumniar y de burlarse de los cristianos, achacándoles errores en las Escrituras ${ }^{11}$, ya que él, como afirma en

8 «Et hi [= interpretes latini] quidem ex grecanis atque caldaicis editionibus, non ex ipso fonte hebraico, latinas nobis ediderunt tra[ns]lationes. In quibus ipsi preter suorum prothotiporum varietates, ne dicam errores, proprias etiam addiderunt dissonantias, scilicet, unusquisque pro captu intellectus sui ... Hinc igitur accidit apud nos tam frequens in sacri scripturis veteris testamenti differentia atque varietas, adeo ut in plerisque earum locis non facile, fuerit olim certum et indubitatum accipere testimonium ad confirmanda fidei nostre dogmata» (Prefacio, fol. $1 \mathrm{v}$ ).

$9 \ll_{\ldots}$. totam Veteris Testamenti scripturam ex ipsismet hebreorum originalibus correctissimis nobis reddere conatus est latinam quatenus nova illa sua editione sacram Bibliam haberemus castigatissimam, sinceram atque hebraice veritati germanam» (Prefacio, fol. 1v).

10 Todo esto lo hizo San Jerónimo en su traducción «quatenus omnia quantum benefieri posset nobis redderet clarissima et scripture hebraice literalem sensum latino sermone depromeret, reiectis scilicet erroribus priorum interpretum» (Prefacio, fol. 1v, col. 2).

11 "Quare in prologo super librum Iosue ait: Quod hac sua editione ablata est perfidis iudeis occassio calumniandi atque irridendi christianos, veluti Bibliam corruptam habentes et in erroribus multis circa rectam fidem allucinantes» (Prefacio, fol. 1v, col. 2). Así se expresaba San Jerónimo en su prólogo al libro de 
el prólogo galeato al libro de los Reyes, corrigió los errores de las antiguas traducciones ${ }^{12}$.

Sin embargo, aún después de la traducción latina de San Jerónimo, los judíos han continuado afirmando con la misma insistencia que el texto hebreo original es el único válido para ser interpretado ${ }^{13}$.

De ahí que Ciruelo pensara que sería sumamente útil y práctica una traducción latina de la Biblia hebrea ad verbum, tal cual los judíos la desean, sin adición ni omisión alguna y sin ningún cambio en el orden de las palabras ${ }^{14}$.

Tal versión literal ad verbum de la Biblia acarrea ciertamente solecismos y barbarismos, pero entraña ciertas ventajas.

La primera utilidad es de orden apologético: demostrar lo infundado de la calumnia judía sobre la corrupción de la Biblia

Josué: «Quae enim audientis utilitas est nos laborare sudare et alios detrahendo laborare, dolere Iudaeos quod calumniandi eis et inridendi Christianos sit ablata occasio, et ecclesiae homines id despicere, immo lacerare, unde adversarii torqueantur? Quod si vetus eis tantum interpretatio placet, quae et mihi non displicet, et nihil extra recipiendum putant, cur ea quae sub asteriscis et obelis vel addita sunt vel amputata, legunt et non legunt? Quare Danihelem iuxta Theodotionis translationem ecclesiae susceperunt? Cur Origenem mirantur et Eusebium Pamphili cunctas editiones similiter disserentes? Aut quae fuit stultitia, postquam vera dixerint, proferre quae falsa sunt? Unde autem in Novo Testamento probare poterunt adsumpta testimonia, quae in libris veteribus non habentur? Haec dicimus, ne omnino calumniantibus tacere videamur" (Biblia sacra iuxta Vulgatam versionem, ed. Robertus WEBER [Stuttgart 1975] pág. 285).

${ }^{12}$ En el referido prólogo San Jerónimo hace una defensa de la veritas hebraica: «Lege ergo primum Samuhel et Malachim meum; meum, inquam, meum; quicquid enim crebrius vertendo et emendando sollicitius et didicimus et tenemos, nostrum est. Et cum intellexeris quod antea nesciebas vel interpretem me aestimato, si gratus es, vel parafrasten, si ingratus, quamquam mihi omnino conscius non sim mutasse me quippiam de hebraica veritate. Certe si incredulus es, lege graecos codices et latinos et confer cum his opusculis, et ubicumque inter se videris discrepare, interroga quemlibet Hebraeorum cui magis accomodare debes fidem, et si nostra firmaverit, puto quod eum non aestimes coniectorem, ut in eodem loco mecum similiter divinarit» (Biblia sacra iuxta Vulgatam versionem loc. cit.).

13 «... adhuc contendit paraphrasim sive grecam sive latinam non sufficere ad intelligentiam sacre scripture, sed necessariam esse interpretationem eius proprie dictam quae precise ad verbum procedat, hoc est, sine alicuius verbi additione, $\mathrm{sub}[\mathrm{s}] \mathrm{tractione}$ aut ordinis permutatione atque penitus observata phrasi hebraici idiomatis» (Prefacio, fol. 1v, col. 2).

14 «... ego nihilominus existimavi in publicam utilitatem ecclesie Dei fore imo et prorsus oportere ut apud nos ederetur aliqua interpretatio latina sacre biblie hebraice praecise ad verbum atque eo modo quo eam iudei desiderant, sine additione, sub[s]tractione aut verborum permutationem» (Prefacio, fol. 1, col. 2). 
cristiana. En efecto, los judíos no tendrán ya ocasión de queja si en la versión latina se hace corresponder exactamente la palabra latina con la hebrea, de modo que resulte «a la par una Biblia hebrea y latina». Además esta traducción literal demostrará que la versión de San Jerónimo es fiel ${ }^{15}$.

La segunda utilidad consiste en que corrige los errores que escritores e impresores han introducido en las versiones de la Biblia («qui quotidie accidunt in sacris libris ex eorum incuria»). De las versiones antiguas, la griega y la aramea son las más venerables; pero aun así se apartan en muchos lugares del texto hebreo original, lo cual no ocurre, o si ocurre es rarísimo, en la versión de San Jerónimo ${ }^{16}$.

Ciruelo destaca la calidad de la versión de San Jerónimo, hasta el punto de que intérpretes judíos, como «R. Salomón, R. Moisés, R. Leví, R. Abraham», han recurrido a ella para elucidar muchos lugares oscuros.

Hay dos razones por las que los traductores de la Septuaginta pudieron introducir desviaciones en el texto: o porque no conocían suficientemente el griego o porque no quisieron desvelar plenamente los arcanos de la Ley ${ }^{17}$.

Aquí encuentra Ciruelo la ocasión para explicar las circunstancias personales que le han llevado a la empresa traductora. En efecto, los judíos han sido siempre reacios a comunicar los secretos de la Ley a los gentiles. Sin embargo, dice el daroquense, en todos los tiempos Dios ha llevado judíos a la Iglesia que han enseñado luego a los cristianos los secretos de la len-

15 «... primo quidem ad penitus convincendam iudeorum proterviam atque prohibendam in nos eorum iam dictam calumniam quod procul dubio nulla alia via melius fieri posset quam si vocibus singulis hebraicis singule inscribirentur voces Latine. Nam inde resultaret una Biblia simul Hebraica et Latina. Hoc est, Latina in nullo penitus discrepans a veritate fontis hebraici qua habita fidelis theologus vel mediocriter eruditus facile posset cum hebreis infidelibus disputare ad probandum eis nostre Biblie latine, quam divus Hieronimus edidit, veritatem illibatam; adeo quod in nullo fere loco discrepet a vero sensu hebraice Biblie iudeorum, quamvis in alia phrasi verborum hoc est latina» (Prefacio, fol. 2r, col. 1).

16 «... sed nihilhominus ille in plerisque locis deviant ab hebraica veritate: non solum in verbis sed etiam in sensu literali quod in paraphrasi Hieronimi vix aut rarissime invenitur» (Prefacio, fol. 2r, col. 2).

17 «Potest etiam dici quoad communis conditio hebreorum est ut nulli homini incircunciso velint sue lingue hebraice secreta in totum revelare et perfecte docere, sed semper inter veritates admisceant falsitates» (Prefacio, fol. 2r, col. 2). 
gua hebrea. Y eso es lo que ha ocurrido precisamente en su tiempo ${ }^{18}$. Señala cómo en torno al año 1500 en España se han convertido al cristianismo una serie de judíos «doctissimi in sacra Biblia hebraica». Estos han enseñado a los cristianos los «secretos del Antiguo Testamento». En esta conyuntura de los tiempos ha nacido Ciruelo, que a la edad de cuarenta años se puso a aprender hebreo con esos cristianos conversos del judaísmo (fundamentalmente con Alfonso de Zamora) y permaneció constante en su estudio hasta que progresó suficientemente como para entender medianamente la Biblia. Consciente como era de la necesidad de una versión literalísima (ad verbum) de la Biblia hebrea, buscó ayudas económicas de ciertos prelados y al no obtenerlas él mismo cubrió los gastos de su propio peculio. Para realizar su obra se ayudó de léxicos hebreos y de las tres versiones fundamentales, la latina, la griega y la caldea ${ }^{19}$.

Pero señala que no tradujo de esa manera todos los libros de la Biblia hebrea, sino sólo aquéllos en los que yacen los fundamentos de la fe católica; y concreta: «libros legales, propheta-

\footnotetext{
18 «.. hoc bonum maxime effecit Deus in diebus nostris in quos iam fines seculorum venerunt» (Prefacio, fol. 2r, col. 2).

19 «Quare prope annos Christiane salutis mille et quinientos hanc promissionem implere volens noster deus precipue in hac nostra Hispania (in qua erant multe Iudaeorum achademie) illuminavit sua gratia plurimos eorum abstulitque velamen cecitatis a cordibus suis e quibus nonnulli viri plane doctissimi in sacra Biblia hebraica baptismum et fidem Christi devote susceperunt, effectisque iam Christiani sincere veraciter et sine fictione ulla nos docuerunt veteris testamenti secreta litteralia. Ego igitur hanc temporis opportunitatem nactus: cepi am quadragenarius litteras hebraicas ab eis discere: vetus testamentum cum ipsis conferre per utrumque simul contextum hebraicum et latinum, nec contentus sola praxi constructionis, volui etiam eorum dicduc idest artem grammaticam intelligere et exercere et ita paulatim praevio lumine divine gratie in spatio fere viginti annorum eousque profeci ut hebraicam Bibliam mediocriter intelligerem. Sciens igitur eius quam dixi interpretationis ad verbum neccessitatem in ecclesia Dei super vetus testamentum, post requisitos a me quosdam ecclesie prelatos, quorum ductu atque impensis hec res pie ageretur eosque videns circa eam frigidissimos ac indevotos, decrevi, iam senior etate, sed zelo Dei et nostre religionis succensus, proprio marte ac sumptibus meis huiuscemodi opus aggredi quod et prosequtus sum spem habens in Deo meo ... adiutus etiam presidio magistrorum meorum simul atque lexicorum hebraicorum adminiculo ac denique trium paraphrasum principalium consortio latine videlicet graece et chaldaice opus hoc divinum prosequtus sum et ad finem usque perveni» (Prefacio, fol. 2v, col. 1).
} 
les et himnidicos, qui ab hebreis thillim dici consueverunt, id est, laudes Dei. Hi sunt libri Iob, David et Salomomis» ${ }^{20}$.

Ya en el prefacio que dedica al lector, Ciruelo señala los solecismos que introduce en la versión y a los que le obliga el carácter y el propósito de su empresa. Así de sacerdos construirá el verbo sacerdotare, de mitra, mitrare, de aure, auriculare, etc., siempre según el espíritu de la lengua hebrea. Por igual razón construirá voco con dativo, servio con acusativo y los numerales (a partir de diez) con el objeto contado en singular. La razón de todo ello, vuelve a repetir, es para que se pueda captar el original hebreo en su idiosincrasia ${ }^{21}$ y sirva a los teólogos católicos ${ }^{22}$.

En otro prólogo que el mismo Ciruelo compuso a otra traducción suya latina interlineal (Ms. de El Escorial G-I-4), dedicado al cardenal Fonseca, abunda en las ideas ya expuestas. Dice que a lo largo de los tiempos Dios suscitó traductores del texto hebreo bíblico, primero griegos, luego caldeos y por último latinos. San Jerónimo hizo una versión latina del texto. Como intentaba reproducir el sentido fielmente y con claridad, omitió a veces palabras y añadió otras, cambiando en general el orden. Pero ya avisó que en caso de dificultad se recurriera siempre a los textos originales.

Para advertir de las variantes, el Cardenal Cisneros ordenó confeccionar un léxico y mandó editar la obra de Nicolás de Lira. Pero esos instrumentos lo que hacen es complicar las cosas y olvidar que los dos fines principales de la edición de las Escrituras es acrecentar la fe y refutar a los judíos incrédulos que achacan a Jerónimo haberlas corrompido. Por esa razón Ciruelo se ha decidido a hacer una versión «hecha palabra por palabra», «de tal forma que a cada palabra hebrea correspondiera la correspondiente latina superpuesta, lo cual ahorraría

20 Resulta, pues, que o no tradujo todos los libros que se propuso traducir o que no nos han llegado todas sus traducciones. Nos faltarían las traducciones literales de Jeremías, Ezequiel, Salmos (y ¿Proverbios?, ¿Eclesiatés?).

21 «... ea ratione factum est quatenus illa originalis lingua hebrea nobis representaretur in sua phrasi et quantum ad proprietates grammaticas singulorum vocabulorum eius, quas ex nostra interlineari glossa latina facile cognoscerit poterit quicumque advertens ad eas» (Prefacio, fol. 3r, col. 1).

22 «... sed nostris theologis veritatem fontis hebraici quibus potuimus verbis latinis explicare voluimus» (Prefacio, fol. 3v, col. 1). 
el trabajo de tener que manejar tantos libros y favorecería además a la de San Jerónimo, que es la más próxima y cercana al original hebreo, siempre que se conserve auténtica» ${ }^{23}$. Señala Ciruelo que, en estos tiempos en que hay muchos cristianos que saben hebreo, ese trabajo es posible.

De todo lo dicho se concluye que Ciruelo, bien que ayudado y asistido por el propio Alfonso de Zamora, es el autor de la traducción latina interlineal «de verbo ad verbum». Había comenzado la obra en 1527, cuando tenía cincuenta y un años y llevaba once estudiando hebreo, y la concluyó en 1538 , a los 62. Entiendo, pues, que no tenía razón el P. Llamas cuando atribuía la traducción latina a Alfonso de Zamora basándose en tres razones: 1) que los colofones lo atestiguan claramente, cuando en realidad no hay ni un solo que afirme tal extremo; 2) que la caligrafía es la propia del judío converso, lo que no vale para la latina; y 3) que el Dr. Ciruelo apenas sabía hebreo, pero cuando comenzó el trabajo llevaba once años ininterrumpidos de estudio de esa lengua con excelentes hebraístas.

Para el P. Llamas la versión se hizo como material de la Políglota de Alcalá, cuando Ciruelo era tan solo colegial ${ }^{24}$, y su labor como teólogo fue simplemente la de garantizar que la versión no se oponía a la fe ${ }^{25}$. Según Llamas, Alfonso de Zamora puso su traducción latina a nombre de Ciruelo para evitar que la rechazaran los círculos de estudiosos donde había muchos antisemitas ${ }^{26}$.

De mi interpretación de los dos prólogos referidos queda claro que no hay fundamento para las suposiciones del P. Llamas.

Ciruelo fue, por tanto, uno de los primeros que en la edad renacentista hizo una versión interlineal «de verbo ad verbum»

${ }^{23}$ Sigo la versión de José Llamas, «Documental inédito de exégesis rabínica en antiguas universidades españolas», Sefarad 6 (1946) págs. 289-231.

${ }^{24}$ La cronografía lo desmiente. Cuando Ciruelo comienza esta empresa, la Políglota de Alcalá ya llevaba bastantes años impresa.

25 Llamas «Documental inédito» pág. 294. François SECRET, «Pedro Ciruelo: Critique de la Kabbale», Sefarad 19 (1959) págs. 48-77, recogía y aceptaba la opinión del P. Llamas: «ne jouit-il que le rôle de garant de la partie théologique et doctrinale» (pág. 52).

${ }^{26}$ Llamas «Universidad de Salamanca» pág. 266. 
del texto hebreo bíblico, aun cuando Sanctes Pagnino publicó su traducción literal interlineal de la Biblia en 1527 y la Biblia Políglota Complutense ya había publicado también la columna griega con traducción interlineal e igual técnica emplearía más tarde la Biblia de Amberes ${ }^{27}$.

En los prólogos de Ciruelo hay varios puntos que merece la pena considerar siquiera brevemente.

\subsection{La acusación judía de que las versiones cristianas de la} Biblia (latinas) han falsificado el texto hebreo original

Esta acusación ya está documentada desde antiguo ${ }^{28}$ y suele ser un motivo bastante frecuente en las obras de polémica anticristiana ${ }^{29}$.

Hay que diferenciar esa acusación de la recriminación y reproche que hacen los judíos a los cristianos de interpretar arbitrariamente las Escrituras. Las palabras de Ya'acob ben Reubén son significativas: 'Tú trastocas las Escrituras, las interpretas a tu arbitrio. Así puedes alterar toda la Torá y todos los Profetas diciendo que todo ha sido dicho de vuestro Mesías' ${ }^{30}$.

\footnotetext{
27 Véase Llamas «Documental inédito» pág. 294.

28 A ella hace referencia San Jerónimo en el mencionado prólogo de Josué: «... dolere Iudaeos quod calumniandi eis et inridendi Christianos sit ablata occasio" (véase supra, nota 11).

${ }^{29}$ Véase, por ejemplo, Ya'acob ben Reubén (siglo XII), Milhamot ha-Šem, ed. Y. Rosenthal (Jerusalén 1963) págs. 12, 78, 112 y 136, quien además señala que en las versiones bíblicas cristianas hay algunos elementos que no sólo no se hallan en el texto hebreo, sino ni tan siquiera en la versión de San Jerónimo (Milhamot ha-Šem pág. 136); Die Disputationen zu Ceuta (1179) und Mallorca (1286): Zwei antijüdische Schriften aus dem mittelalterlichen Genua, ed. Ora LIMOR (München $1994)$ pág. 249; Šim ón ben Sémaj Durán, Kéšet u-maguén, ed. Prosper MURCIANO (Xerox University Microfilms 1975) pág. 45: 'Jerónimo, que tradujo y trasladó la Torá al latín, cambió y se confundió en muchos lugares'; Yosef Albo, Séfer haTcarim, ed. Isaac HusIK (Philadelphia 1929-1930) vol. III pág. 25. Gilbert CRIsPIN, Disputatio Iudaei cum Christiano ( $P L 159$, pág. 1027), ante la acusación de corrupción textual, señala que su texto se basa en la traducción de los LXX versión hecha por judíos antes de la aparición del cristianismo y admitida por ellos; de ahí que si hay variaciones respecto al texto hebreo, no pueden censurar por ello a los cristianos.

${ }^{30}$ Milhamot pág. 70; Yehudá ben Barzilay, Sefer ha- Ttim, ed. Y. SCHOR (Berlin, 1903 ) pág. 77; W. BACHER, «Unedited Chapters of Jehudah Hadassi's 'Eshkol Hakkofer», JQR 8 (1896) pág. 432.
} 
Pareja a esta incriminación corría entre los cristianos otra achacando a los judíos la corrupción del texto bíblico por motivos apologéticos, esto es, con la finalidad de quitar a los cristianos algunas de las bases teológicas de sus creencias. Esta inculpación aparece ya en los Diálogos de San Justino (siglo II), aunque se refiere como tal al texto de los $\operatorname{LXX}^{31}$.

San Agustín (siglo IV) recrimina igualmente a los judíos el introducir ciertos cambios en sus códices para disminuir los textos que corroboran la tesis cristiana ${ }^{32}$. Alvaro de Córdoba (siglo IX) también acusaba a los judíos de haber introducido cambios en las Escrituras para eliminar los testimonios en favor de Cristo ${ }^{33}$.

Los musulmanes también imputaban a los judíos el haber falsificado las Escrituras, aunque su acusación era de mayor envergadura. No se trataba de la modificación de un texto u otro, sino de que todas las Escrituras después de estar un largo tiempo ocultas o perdidas fueron «reescritas» por Esdras el Escriba. De ahí que los cambios por él introducidos fueron mucho más allá de las simples «correcciones de los escribas» (ticuné soferim) ${ }^{34}$. Maimónides en la epístola del Yemen se

31 «Neque illud etiam vobis ignoratum velim, permultas Scripturas, ex quibus perspicue hunc ipsum, qui cruci affixus fuit, et Deum, et hominem et crucifixum, et morientem praedicatum esse demonstratur, omnino ab eis ex illa interpretatione, quam senes apud Ptolomaeum adornarunt, deletas fuisse» (Dialogus cum Tryphone Iudaeo, PG 6, págs. 644-645); concretamente les reprocha haber suprimido pasajes de Esdras, Jeremías y Salmos.

32 «Iudaeos vero, dum nobis invident, quod lex et prophetae ad nos interpretando transierint, mutasse quaedam in codicibus suis, ut nostris minueretur auctoritas» (De civitate Dei, Lib. XV, cap. 11 [Series Latinas 48, «Corpus Christianorum»]. San Agustín interpretaba, por otra parte, que las variantes o cambios de la versión de los LXX respecto al texto hebreo no había que entenderlos siempre como errores, sino como «innovaciones» proféticas: «Non enim est illa diversitas putata mendositas, nec ego ullo modo putanda existimo: sed ubi non est scriptoris error aliquid eos divino spiritu, ubi sensus esset consentaneus veritati et praedicans veritatem non interpretantium munere, sed prophetantium libertate aliter dicere voluisse credendum est» (De civitate Dei, Lib. XV, cap. 14).

${ }_{33}$ Epistolae ( $P L 121$, págs. 486-487). Véase E. AsHTOR, The Jews of Moslem Spain (Philadelphia: The Jewish Publication Society, 1992) vol. I pág. 76.

${ }_{34}$ Véase, por ejemplo, la denuncia de Ibn Hazm (Camila ADANG, Islam frente a Judaísmo [Madrid 1994] págs. 70ss.); Norman ROTH, «Forgery and Abrogation of the Torah: A Theme in Muslim and Christian Polemic in Spain", Proceedings of the American Academy for Jewish Research 54 (1987) págs. 203-236. 
hace eco de las acusaciones musulmanas: «Debido a que no encontraron a su favor ningún argumento en toda la Torá, ya sea verso, pensamiento o símil que los corroboren, se sintieron necesitados de afirmar: "Habéis trastocado la Torá, la habéis cambiado, habéis borrado de ella el nombre de fulano"» ${ }^{35}$.

Pero la acusación cristiana contra los judíos de falsificar las Escrituras no fue general. El propio San Agustín afirmaba que los judíos eran los archiveros de las Escrituras que testimoniaban la veracidad de las profecías sobre Cristo ${ }^{36}$.

El Papa Inocencio III en su Constitutio pro Iudaeis (1119) afirmaba que los judíos no debían de ser oprimidos severamente «quia tamen per eos fides nostra veraciter comprobatur» ${ }^{37}$. Es decir, que tanto San Agustín como Inocencio III y tantos otros reconocían la autenticidad y veracidad de las Escrituras hebreas.

Por parte judía se era consciente de que en ese punto coincidían judíos y cristianos. Así lo reconoce, por ejemplo, Šim ón ben Sémaj Durán al afirmar que judíos y cristianos tienen una misma Biblia coincidente ${ }^{38}$. El célebre traductor provenzal Yehudá ben Majir (siglos XII-XIII) en una carta que dirige al rabino de Barcelona Selomó ben Adret afirma que los cristianos respetan y aceptan las versiones que los judíos hacen de las Escrituras a las lenguas romances ${ }^{39}$. El mismo Maimónides no desaconsejaba la discusión de la Torá con los cristianos, ya que unos y otros -judíos y cristianos- aceptaban las mismas

35 Vid. Cartas y Testamento de Maimónides, ed. Carlos del VAlle (Córdoba 1988) XXIII.23, pág. 156. Maimónides se refería a textos como los de El Corán 7:157, donde se afirma que tanto en la Torá como en los Evangelios se alude a Mahoma. Cfr. Pedro de la Caballería, Tractatus Zelus Christi contra Iudaeos, Sarracenos et Infideles (Venetiis 1592) notas 888 y 889 ; y Ad. NEUBAUER, «Documents inédits», REJ 5 (1882) pág. 53.

36 «Nobis quidem illae sufficiunt, quae de nostrorum inimicorum codicibus proferuntur, quos agnoscimus propter hoc testimonium, quod nobis inviti perhibent eosdem codices habendo atque servando, per omnes gentes etiam ipsos esse dispersos, quaqua versum Christi Ecclesia dilatatur» (De civitate Dei XVIII.46 [PL 41, págs. 608-609])

37 Véase la cita en nuestras «Notas histórico-críticas», en Marcela TCHIMINo C. del VAlle, Declarante de los judíos (Madrid 1996) pág. 38.

${ }^{38}$ Kéšet u-maguén pág. 63.

39 J. Perles, R. Salomo ben Abraham ben Adereth: Sein Leben und seine Schriften nebst handschriftlichen Beilagen (Breslau 1863) pág. 37. 
Escrituras divinas ${ }^{40}$. Un teólogo, contemporáneo de Ciruelo, Pedro de Palencia, achacaba a ignorancia las acusaciones de falsificación de las Escrituras, mencionando expresamente a Melchor Cano (1509-1560). Hasta Cristo, argüía, no pudo haber habido corrupción, ya que Cristo la habría denunciado; tampoco hubo falsificación desde Cristo a San Jerónimo, ya que este tradujo la Vulgata desde los textos originales auténticos, afirmando que los hebreos tenían en Venecia un códice que venía de Esdras. Concluía así Pedro de Palencia: «y es disparate decir que los judíos alteran en los escriptos a fin de que en ellos no se hallasen tan clara noticia de los misterios de la fe, porque esto era querer ellos carecer de la verdadera Scriptura» ${ }^{41}$.

En este consenso se fundamenta el principio de la hebraica veritas, es decir, que el criterio irrecusable y único en definitiva para toda cuestión referente a la Biblia hebrea es el texto hebreo bíblico. Este principio fue reconocido por San Jerónimo cuando para cualquier cuestión dudosa o controvertida respecto a la traducción reenviaba en último término al texto hebreo como albacea autoritativo y autorizado de la verdad revelada. El principio de la hebraica veritas es admitido por Pedro Alfonso (siglo XII) cuando en el Diálogo acepta la proposición del contrincante, el judío Moisés, de que cualquier «autoridad» que sea aducida de la Escritura lo sea «secundum veritatem hebraicam» ${ }^{42}$. El mismo principio lo acepta Abner de Burgos cuando establece las fuentes desde las que se puede establecer el diálogo entre cristianos y judíos ${ }^{43}$.

\subsection{La Vulgata latina}

Pedro Ciruelo escribe en una época muy cercana a la de algunos autores, como fray Luis de León (1527-1591) y Gilbert

\footnotetext{
${ }^{40}$ Véase su «responsum» a los discípulos de R. Efraim, en mi edición de Cartas y Testamento ... XXXII pág. 243.

${ }^{41}$ Tratado cerca la Regla del Catálogo que disponen la liction de las glosas de Rabinos (1611) BNM, Ms. 1.076, fol. 27b.

${ }^{42}$ Pedro Alfonso de Huesca, Diálogo contra los judios, ed. María Jesús LACARRA (Huesca 1996) pág. 10.

${ }^{43}$ Mostrador de Justicia, Biblioteca Nacional de París, Ms. esp. 43, fol. 28r; cfr. A. GRABOIS, «The Hebraica Veritas and Jewish-Christian Intellectual Relations in the Twelfth Century», Speculum 50 (1975) págs. 613-634.
} 
Genebrardo (1537-1597), que afirmaban que en muchos lugares de la Vulgata latina se podía hacer una traducción mejor ${ }^{44}$. Por defender tal opinión estuvo fray Luis de León tres años preso en las cárceles de la Inquisición ${ }^{45}$.

Pedro Ciruelo se muestra más prudente y viene a confesar que las diferencias de la Vulgata con el texto hebreo se deben fundamentalmente a errores y erratas introducidas en las ediciones de la Vulgata.

Sólo unos pocos años más tarde el Concilio tridentino (15451563) sancionaba dos decretos, uno sobre la canonicidad de la Vulgata y otro sobre su autenticidad. El Concilio declaraba que la edición corriente latina, la Vulgata, era auténtica, es decir, conforme a los originales, no en su texto como tal, sino en cuanto testimonio de una doctrina en la que no se hallaba herejía alguna; de ahí que, en consecuencia, podía ser empleada en las lecciones, lecturas públicas y discusiones. El criterio de canonicidad era doble: «prout in ecclesia catholica legi consueverunt» $\mathrm{y}$ 《et in veteri vulgata latina editione habentur» ${ }^{46}$.

Para mostrar el valor de la Vulgata Pedro Ciruelo recoge una idea que circulaba en su tiempo, a saber, que los exégetas hebreos recurrían a la versión jeronimiana para dilucidar sus dudas sobre determinados lugares bíblicos. E1 traductor latino del Tišbí de Elías Levita (Basilea 1557, Prefacio) se hace eco de esas corrientes. Después de haber señalado que Abraham ibn 'Ezrá (1092-1167) sabía hebreo, arameo, árabe y griego, di-

\footnotetext{
${ }^{44}$ Fray Luis de León afirmaba: «Multa sunt in editione Vulgata latina in his quod pertinet ad misterium fidei, sacramenta eclesie et mores fidelium quod melius possunt vertinune quam ab interprete latino versa sunt" (citado por Pedro de Palencia, Tratado cerca la Regla del Catálogo ..., BNM, Ms. 1076, fol. 24b). La citada proposición de fray Luis de León la consideraba Pedro de Palencia como falsa, pero pensaba que sí era aceptable admitir que algunos pasajes estaban más claros en el texto hebreo que en el latino (fol. 25a).

${ }^{45}$ Véase Pedro de Palencia, BNM, Ms. 1076, fol. 24a; E. D. Carretero, «Luis de León", Diccionario de Historia Eclesiástica de España (Madrid 1972) vol. II págs. 1286-1288.

${ }^{46}$ «Si quis autem libros ipsos integros cum omnibus suis partibus, prout in Ecclesia catholica legi consueverunt et in veteri vulgata latina editione habentur, pro sacris et canonicis non susceperit, A. S.» (BONACCORSI, Questioni Bibliche [Bologna 1904] págs. 8-11).
} 
ce: «cuius impudentie sit, hunc maiorum suorum studio, industria atque opera destitutum, tam cumulatam variorum rerum cognitionem, ex unius Hieronymi translatione hausisse?». De Raší (1040-1105) señala que no sabía latín y rechaza que se sirviera por tanto de las versiones latinas («... ut tamen is dicetur ex translationibus Christianorum, sive graecis, sive latinis, tantus evasisse? cum in Christianorum scripta tam iniquus semper extiterit, ut ne inspectione quidem ea dignaretur»). De David Quimhí resalta su grandeza y cuestiona que se haya aprovechado de la traducción de San Jerónimo («Hic autem si ad illud eruditionis fastigium Hieronymi opera atque subsidio provectus, quid, quaeso, auctoritates et sententias is scriptis suis allegat?»). Lo mismo viene a decir de Elías Levita, destacando la repugnancia que tienen los judíos al latín por identificarlo con la lengua que utilizan los cristianos para defender su religión («Qui non modo christianorum scripta, tanquam a norma recte religionis aliena, execrantur et damnant, verum etiam Latinum sermonem, suae religionis defendendae ac retinendae ardore quodam, proterve nimius aspernabantur»).

\section{El poema hebreo de Alfonso de Zamora}

El poema hebreo de Alfonso de Zamora es un šir merubáa, esto es, un poema de estrofas de cuatro esticos, donde los tres primeros tienen una misma rima, diferente en cada verso, mientras que el cuarto tiene una rima común a todos los versos (aaab, cccb, dddb ...) ${ }^{47}$. Carece de metro.

Como confiesa el propio autor, el poema muestra la utilidad y necesidad del libro, esto es, de la traducción latina interlineal, ad verbum, del texto hebreo bíblico hecha por Pedro Ciruelo. Recuerda que San Jerónimo hizo una traducción fiel de las Escrituras, pero en las continuas reediciones que de ella se hacen se introducen erratas que son seguidas luego por los ignorantes. San Jerónimo tuvo en cuenta, sin embargo, que el texto hebreo tenía que ser siempre de obligada referencia. Por eso aconseja en su prefacio del Pentateuco que en caso de du168.

47 Véase mi libro El diván poético de Dunash Ben Labrat (Madrid 1988) pág. 
da se consulten los textos originales (o los intérpretes hebreos solventes) ${ }^{48}$.

La nueva versión interlineal literal ad verbum va a permitir controlar la exactitud de toda traducción de modo que arrumbe y desplace las incorrectas; sólo el texto original hebreo es el único estable, firme y sólido.

\section{El POEMA}

He aquí el texto hebreo del poema seguido de su traducción.

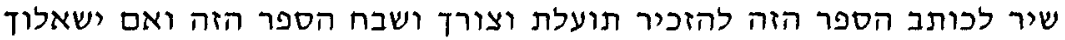

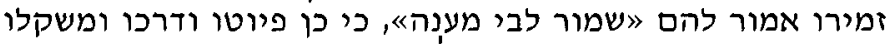

$$
\begin{aligned}
& \text { 1] עם אל המשוחים שמעו דברי אל נכוחים } \\
& \text { ושמרום מפחים ומחרבות צורים }
\end{aligned}
$$

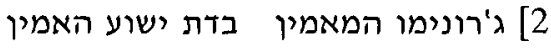

$$
\begin{aligned}
& \text { נטה לצד ימין בדמין בדריו נבחרים יאומים }
\end{aligned}
$$

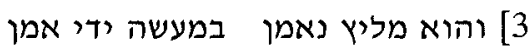

$$
\begin{aligned}
& \text { כמו לבוש ארגמן מכבוץ מכד לנהדרים ימשים }
\end{aligned}
$$

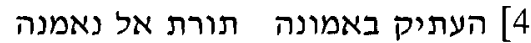

$$
\begin{aligned}
& \text { ובכל שנה ושנה בתמה הדפיסוה נמהרים נמנה ורים }
\end{aligned}
$$

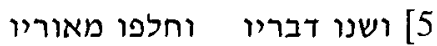

$$
\begin{aligned}
& \text { והטו אחריו וחריו מעתיקום מאורים בערים }
\end{aligned}
$$

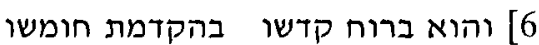

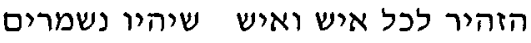

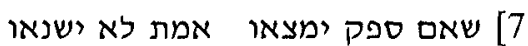

$$
\begin{aligned}
& \text { וללשון קדש יבאו ומצו ויאמינו הדברים יאנותו }
\end{aligned}
$$

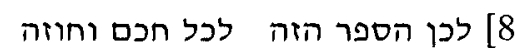

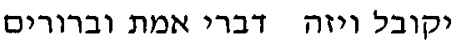

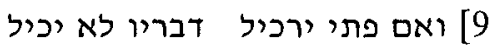

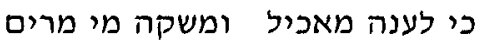

$$
\begin{aligned}
& \text { 10 } \\
& \text { מזהיר לו בגדולה ומלחלה קולה נסתרים }
\end{aligned}
$$

\footnotetext{
48 Alfonso de Zamora se refiere, sin duda, a las palabras de San Jerónimo en su prefacio al Pentateuco: «sicubi tibi in translatione videor errare, interroga $\mathrm{He}$ breos, diversarum urbium magistros consule» (Biblia Sacra iuxta latinam vulgatam versionem ... Recensuit D. Henricus Quentin [Romae 1936]).
} 


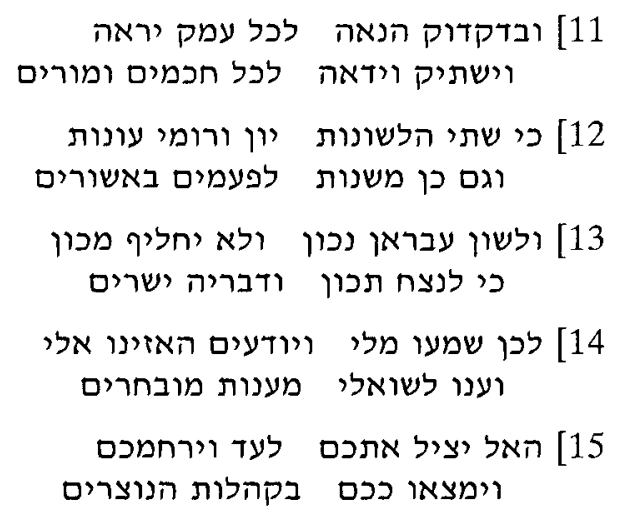

Poema del amanuense de este códice para resaltar el provecho y la necesidad y la loa de este libro. Si te preguntan [cuál es] su melodía, contesta [que es la de] «Guarda, corazón mío, una respuesta» ${ }^{49}$, porque tal es su piyyut y su forma y su metro.

1] Pueblo cristiano, escucha las palabras de Dios que son rectas, ¡guárdalas de los lazos y de los cuchillos de pedernal! ${ }^{50}$.

2] Jerónimo el creyente creyó en la religión de Jesús; se encaminó hacia el lado derecho con sus palabras selectas.

3] $Y$ él es intérprete fiel en una obra de artesano experto; como un vestido de púrpura honra a los selectos.

4] Tradujo con fidelidad la Ley de Dios verdadera, pero año tras año [su versión] la imprimen gentes precipitadas.

5] $Y$ cambian sus palabras y alteran sus luminarias $y$ han hecho ir tras ellos a traductores ignorantes.

6] Pero él, con el espíritu de su santidad, en su prefacio al advirtió a todo hombre que fueran precavidos.

49 Incipit de las Azharot de Šelomó ibn Gabirol (cfr. Israel Davidson, Thesaurus of Medieaval Hebrew Poetry [New York 1930] vol. III, pág. 476 [šin núm. 1482]). El poema de Alfonso de Zamora se atiene al de Ibn Gabirol en cuanto a la estructura formal externa que como ya he dicho consta de estrofas de cuatro esticos, rimando entre sí los tres primeros y el cuarto con rima en -im, uniforme en todo el poema: $a a a b, c c c b$, etc.; sin embargo no se mantiene el metro cuantitativo interno del modelo.

so Josué 5:2; se trata de los cuchillos de pedernal que Josué utilizó para la circuncisión, de ahí que posiblemente se refiera a los judíos. 
7] Que si hallasen una duda no aborrezcan la verdad y se alleguen a la lengua santa y crean sus palabras.

8] De ahí que este libro por todo sabio y clarividente será aceptado y esparcirá palabras verdaderas y nítidas.

9] $\mathrm{Y}$ si un necio lo difamara, sus palabras no retendrá, pues le dará a comer ajenjo y aguas amargas le hará beber.

10] Porque palabra con palabra, sin voz de alboroto alguno, le ilustra con amplitud y le desvela las cosas ocultas.

11] Con una precisión admirable contempla toda profundidad, y hace enmudecer y se remonta sobre todos los sabios y

[maestros.

12] Porque las dos lenguas, griega y latina testifican, aunque también trastocan a veces el testimonio.

13] Mas la versión hebrea es correcta y en nada inmuta su

[firmeza, porque eternamente es estable y sus palabras son rectas.

14] Por eso oíd mis palabras y los entendidos que me escuchen y contestad a los que me inquieren respuestas escogidas.

15] Dios os guarde siempre y tenga de vosotros misericordia, y que se hallen [muchos] como vosotros en las comunidades

[cristianas. 


\section{RESUMEN}

Pedro Ciruelo (siglo XVI), filósofo, teólogo y científico, natural de Daroca, hizo una traducción literal interlineal («de verbo ad verbum») de varios libros de la Biblia hebrea. La empresa la comenzó hacia el año 1526 y aún continuaba con ella en 1538. Con motivo de la traducción literal interlineal del Pentateuco (1536), Alonso de Zamora (n. 1474), que al parecer fue su maestro de hebreo y su mentor a lo largo de la traducción, compuso un poema en hebreo para honrar aquel magno trabajo. En este estudio se publica el texto original hebreo (Ms. de la Biblioteca Universitaria de Salamanca, núm. 589 , fol. 274), se traduce al castellano y se expone el significado que el propio Ciruelo y el mismo insigne converso zamorano concedían a la traducción bíblica literalísima.

\section{SUMMARY}

The Darocan-born Pedro Ciruelo (XVI century), philosopher, theologian and scientist, prepared a literal, interlinear (verb for verb) translation of many books of the Hebrew Bible. He began this enormous task ca. 1526, and was still engaged in it twelve years later. In light of the literal, interlinear translation of the Pentateuch (1536), Alonso de Zamora (who apparently was his Hebrew teacher and academic mentor) composed a Hebrew poem in praise of the masterwork. The present article includes the edition of the original Hebrew poetic text (the provenance of which is MS. 589 of the Biblioteca Universitaria of Salamanca, fol. 274), its Spanish translation, and an explanation of the importance that Ciruelo and the converso Alonso de Zamora attributed to the extremely literal translation of the Hebrew Bible. 